\title{
Oral Emulsion in Sachet
}

National Cancer Institute

\section{Source}

National Cancer Institute. Oral Emulsion in Sachet. NCI Thesaurus. Code C149714.

Medicinal product consisting of an oral emulsion presented in a sachet. 